\title{
AS EXPOSIÇÕES UNIVERSAIS COMO MÍDIA PARA A CIRCULAÇÃO TRANSNACIONAL DE SABERES SOBRE $O$ ENSINO PRIMÁRIO NA SEGUNDA METADE DO SÉCULO 19
}

\author{
Klaus Dittrich \\ Korea University, South Korea.
}

\section{Resumo}

O estudo analisa as exposições universais durante a segunda metade do século 19, no que concerne à abordagem da transferência cultural pensada para o campo da educação. Aborda o tema da circulação de saberes sobre educação e, em especial, sobre os progressos no ensino primário, possibilitada pelo movimento de alguns atores, assim como de seus objetivos específicos em torno a este fim. Concentra-se em examinar quatro países: Japão, França, Estados Unidos e Alemanha e argumenta que a transferência cultural acerca do ensino primário foi operada por meio das seções que, nas exposições universais, expuseram os progressos quanto aos objetos pedagógicos, aos documentos redigidos, às maquetes, às plantas de prédios escolares, bem como aos modelos adotados pelas trocas e aos aprendizados das experiências do estrangeiro. Verifica, ainda, as diferentes influências socioculturais que nortearam a busca de modelos pelas referidas nações.

Palavras-chave: exposições universais, circulação de saberes, ensino primário, século 19, transferência cultural.

\section{THE UNIVERSAL EXHIBITIONS AS MEDIA FOR THE TRANSNATIONAL KNOWLEDGE CIRCULATION ABOUT PRIMARY EDUCATION IN THE MID-19TH CENTURY}

\section{Abstract}

The study examines the approach of cultural transfer thought to the educational field of universal exhibitions during the second half of the 19th century. The issue of knowledge circulation on education was adressed and, specially, the progress in primary education, made possible by the movement of some actors, as well as their specific goals around this subject. Focuses on analyzing four countries: Japan, France, Germany and the United States and discuss that cultural transfer on primary school was operated by the sections that, in the universal expositions, explored the progresses on pedagogical objects, written documents, designs of school buildings, as well as models adopted by the exchanges and learning experiences from abroad. Finally, verifies the different sociocultural influences that guided the search for models by those nations.

Key-words: universal exhibitions, circulation of knowledge, primary, nineteenth century, cultural transfer. 


\section{LES EXPOSICIONES UNIVERSALES COMO MEDIA PARA LA CIRCULACIÓN DEL TRANSNACIONAL DE LOS CONOCIMIENTOS SUR LA ENSEÑANZA PRIMARIA EN LA SEGUNDA MITAD DEL SIGLO 19}

\section{Resumen}

El estudio examina las exposiciones universales de la segunda mitad del siglo 19, a partir del enfoque de la transferencia cultural en el campo de la educación. Trata del tema de la circulación del conocimiento en la educación y, en particular, sobre los progresos en la enseñanza primaria, que fue posible por el movimiento de algunos de los actores, así como sus objetivos específicos sobre ese fin. Se centra en el examen de cuatro países: Japón, Francia, Alemania y los Estados Unidos y sostiene que la transferencia cultural en la enseñanza primaria era operada por secciones que, en las exposiciones universales, han expuesto los avances en relación a los objetos pedagógicos, los documentos escritos, los modelos, los planes de los edificios escolares, así como los modelos adoptados por los intercambios y experiencias de aprendizaje en el extranjero. También verifica las distintas influencias socioculturales que guiaron la búsqueda de modelos en esas naciones.

Palabras-clave: exposiciones universales, circulación de conocimientos, siglo 19, transferencia cultural, enseñanza primaria.

\section{LES EXPOSITIONS UNIVERSELLES COMME MEDIAS POUR LA CIRCULATION TRANSNATIONALE DES SAVOIRS SUR L'ENSEIGNEMENT PRIMAIRE PENDANT LA SECONDE MOITIE DU $19^{\mathrm{émme}}$ SIECLE}

Résume

L'étude analyse les expositions universelles pendant la seconde moitié du $19^{\text {èmme }}$ siècle, en ce qui concerne l'approche de transfert culturel pensé pour le domaine de l'éducation. Elle touche également au thème de la circulation de savoirs sur l'éducation et, en particulier, sur les progrès dans l'enseignement primaire, rendu possible grâce au mouvement de quelques acteurs, ainsi que de leurs objectifs spécifiques autour de ce but. Elle se concentre à examiner quatre pays : le Japon, la France, les États-Unis et l'Alemagne et argumente que le transfert culturel à propos de l'enseignement primaire a été fait par le moyen des sections qui, dans les expositions universelles, ont présenté les progrès sur les objectifs pédagogiques, aux documents écrits, les maquettes, les plans des bâtiments scolaires, ainsi que les modèles adoptés par les échanges et les apprentissages des expériences de l'étranger. Nous y vérifions, encore les différentes influences socioculturelles qui guident la recherche de modèles par les nations citées.

Mots-clé: expositions universelles, circulation de savoirs, enseignement primaire, $19^{\text {èmme }}$ siècle, transfert culturel. 
Introdução

- oi em 1851 que a famosa exposição londrina, The great exhibition of the works of industry of all nations, inaugurou a era das exposições universais. As exposições seguintes foram organizadas em intervalos irregulares, a maior parte em Paris e nos Estados Unidos (Greenhalgh, 1988). A pesquisa recente, principalmente a anglo-saxônica, salienta os fenômenos como a representação do imperialismo e do exotismo e suas percepções para um público de massa ${ }^{1}$. Mas não se pode esquecer que as exposições universais do século 19 foram um dos meios de comunicação para os atores profissionais e científicos (Kroker, 1975).

É especificamente este o caso no campo da educação. A partir de 1862 as exposições universais continham seções escolares ${ }^{2}$, as quais possuíam certo número de elementos que se repetiram em todas as exposições sucessivas. Primeiramente apresentava-se o aspecto físico das instituições educativas, seus planos, depois as fotografias e as escolas-modelo reconstruídas para a exposição. Em seguida, objetos pedagógicos eram apresentados em grande número, de canetas a máquinas de calcular e quadros murais. Além do mais, as exposições se pareciam com bibliotecas, porque continham livros pedagógicos e manuais escolares. Finalmente, trabalhos de alunos tinham a função de provar o sucesso dos métodos aplicados. Além das exposições escolares propriamente ditas, conferências e congressos nacionais foram organizados no contexto das exposições universais a partir de $1876^{3}$.

As exposições universais abarcavam toda a educação, dos jardins de infância às universidades. Entretanto, a ênfase recaía no ensino primário, no ensino técnico e, mais tarde, no ensino superior. Neste artigo vamos nos concentrar no exame do ensino primário, com especial atenção para segunda metade do século 19. Cabe destacar que, em muitos países, tal ensino se encontrava em uma fase de expansão e de institucionalização, o que explica sua forte presença nas exposições.

Os principais atores nos bastidores das exposições escolares eram os gestores, funcionários dos ministérios de educação, professores de instituições privadas e especialistas da educação que, em geral, frequentavam as exposições com muito entusiasmo. Tal interesse se explica, em grande parte, pelo fato de que, para estes atores, as exposições eram um meio de comunicação com seus pares, para além das fronteiras nacionais. Com quais motivações estes especialistas do mundo da educação visitavam estes eventos e preparavam suas próprias exposições? Porque eles investiam em nível transnacional?

As exposições universais eram eventos transnacionais que os gestores do mundo da educação frequentavam com intenções bem específicas. De modo geral, suas

\footnotetext{
${ }^{1}$ Ver, por exemplo, YOUNG, Paul. Globalization and the great exhibition: the victorian new world order. New York: Palgrave Macmillan, 2009.

${ }^{2}$ Ver as contribuições de LAWN, Martin (ed.). Modelling the future: exhibitions and the materiality of education. Oxford: Symposium Books, 2009. Uma das raras monografias sobre a educação nas exposições universais concerne ao Brasil. Ver: KUHLMANN, Moysés Jr. As grandes festas didáticas: a educação brasileira e as exposições internacionais (1862-1922). São Paulo: USP, 1996. Tese (doutorado em Educação). Universidade de São Paulo, Faculdade de Filosofia, Letras e Ciências Humanas.

${ }^{3}$ Ver a edição especial La fabrique internationale de la Science: les congrès scientifiques de 1865 à 1945 , da Revue germanique internationale, 12, 2010.

Hist. Educ (Online) $\quad$ Porto Alegre

v. 17

ก. 41

Set./dez. 2013

p. $213-234$
} 
intenções se resumiam em três práticas diferentes ${ }^{4}$. Primeiramente as exposições eram ocasiões para informar-se sobre o que acontecia no exterior e, se necessário, para transferir elementos estrangeiros para seu próprio contexto ou, por assim dizer, aprender com o estrangeiro. Em segundo lugar, as exposições também permitiam postular o sucesso, ou até mesmo a superioridade da educação de um país em relação a outro, em um contexto de competição entre sociedades imperialistas (Charle, 2001). Em terceiro lugar, as exposições oportunizavam o início da colaboração internacional entre especialistas de diferentes países ${ }^{5}$.

Vamos nos concentrar na primeira intenção e analisar como os especialistas iam às exposições com a finalidade de aprender algo em benefício de seu próprio contexto institucional. A abordagem das transferências culturais, como foi desenvolvida a partir dos anos 1980 sobre o contexto franco-alemão, nos ajuda a analisar estes processos de apropriação (Espagne, 1999). Os teóricos das transferências culturais distinguem diferentes fases nestes processos. De início, uma parte dos atores constata déficits e procura soluções potenciais no exterior. Segue-se uma fase de contato e de mediação. Finalmente o saber estrangeiro é adaptado e institucionalizado, ou então, o que é também possível, recusado. As exposições se prestaram, especialmente, para a fase de contato e mediação. Por ocasião da visitação das missões às exposições, os especialistas escreviam importantes relatórios, testemunhos materiais desta mediação e que constituem a fonte principal do estudo.

Neste artigo vamos nos concentrar em quatro países ou, mais especificamente, sobre atores de quatro países que frequentaram as exposições com a finalidade de se informarem sobre o ensino primário. Para cada país vamos identificar conjunturas, interrogar-nos sobre os atores e os déficits que eles perceberam, analisar suas participações nas exposições e os resultados deste engajamento. Além disso, vamos relacionar as conjunturas, comparar a apropriação dos saberes em diferentes contextos nacionais, o que pode conduzir, talvez, a uma verdadeira história transnacional, que combina as abordagens das transferências culturais e da comparação ${ }^{6}$.

$\mathrm{Na}$ primeira parte examinaremos o caso japonês. Em seguida, veremos que este caso apresenta muitas semelhanças com o caso francês. Na terceira parte, debruçar-nosemos sobre o caso dos Estados Unidos para, finalmente, contrastar estas experiências com o caso alemão.

\section{Japão}

Quando se trata da questão das transferências no campo da educação, o caso mais paradigmático parece ser o do Japão (Schriewer, 2004). Após a abertura forçada do país

\footnotetext{
${ }^{4}$ Esta abordagem se encontra inicialmente desenvolvida em DITTRICH, Klaus. Appropriation, representation and cooperation as transnational practices: the example of Ferdinand Buisson. In: LÖHR, Isabella; WENZLHUEMER, Roland (eds.). The nation state and beyond: governing globalization processes in the nineteenth and early twentieth century. Heidelberg/New York: Springer, 2012 (a ser publicado).

${ }^{5} \mathrm{O}$ conceito de internationalisme gouvernemental é tomado neste caso de HERREN, Madeleine. Hintertüren zur Macht: Internationalismus und modernisierungsorientierte Außenpolitik in Belgien, der Schweiz und den USA 1865-1914. München: Oldenbourg, 2000.

${ }^{6}$ Para um exemplo de combinação de transferência e comparação ver LINGELBACH, Gabriele. Erträge und Grenzen zweier Ansätze: Kulturtransfer und Vergleich am Beispiel der französischen und amerikanischen Geschichtswissenschaft während des 19. Jahrhunderts. In: CONRAD, Christoph; CONRAD, Sebastian (eds.). Die Nation schreiben: Geschichtswissenschaft im internationalen Vergleich. Göttingen:
} Vandenhoeck \& Ruprecht, 2002. p. 333-359.
Hist. Educ. (Online)
Porto Alegre
v. 17
ก. 41
Set./dez. 2013
p. $213-234$ 
para a Europa e para a América do Norte, a partir dos anos 1850, uma parte da elite japonesa decidiu se engajar em um vasto programa reformador, com o objetivo de modelar o arquipélago segundo as sociedades europeias e norte-americanas. Esta estratégia de reformas fundamentais tornou-se a política oficial após a Restauração de Meiji, de 1868, uma mudança de regime que colocou fim a mais de 200 anos de reinado feudal da família dos Tokugawa e restaurou o Imperador como soberano do Japão. Ao assumir o governo, o Imperador anunciou que o Japão devia buscar saberes no exterior (Breen, 1996).

A construção de um sistema escolar fazia parte das reformas (Duke, 2009). O Ministério da Educação - monbushō - foi criado em 1871 e a primeira lei que instaurou um sistema de educação - gakusei - foi promulgada em $1872^{7}$. Neste contexto, é preciso lembrar que o Japão já dispunha de uma taxa de alfabetização relativamente elevada, bem como a educação estava organizada em nível dos principados particulares. O povo recebia uma educação mais simples na classe guerreira dos samurais. Gakusei, a lei de 1872, estipulava que todas as crianças japonesas tinham direito ao mesmo tipo de educação, que o ensino primário tornava-se obrigatório, que a autoridade fosse centralizada no Ministério da Educação e que o país fosse dividido, hierarquicamente, em distritos acadêmicos e escolares. É preciso observar que nesta fase precoce de institucionalização, as mudanças só tomavam efeito lentamente e mais do que a instauração efetiva de um sistema de educação, gakusei indicava o caminho a percorrer ${ }^{8}$.

Gakusei não conseguiu esconder certa inspiração francesa. De uma parte, a referência americana era central para os japoneses. A maior parte dos especialistas estrangeiros - oyatoi gaikokujin - convidados desta área vinha dos Estados Unidos. O americano Marion McCarrel Scott tornara-se professor da nova Escola Normal de Tóquio, onde atuou de 1872 a 1874. Outro americano, David Murray, foi recrutado como conselheiro estrangeiro no Ministério da Educação em 1873 (Yoshiie, 1992). Além deles, dois estudantes japoneses foram enviados a escolas normais americanas para completarem seus estudos pedagógicos.

Nesta fase inicial da institucionalização do sistema educativo nipônico, outros esforços foram necessários e, dentre eles, a frequência às exposições universais foi um meio de comunicação para entrar-se em contato com os progressos estrangeiros.

Após uma missão japonesa ter visitado a exposição londrina de 1862, o Japão, ainda sob a égide do antigo regime, participou oficialmente, pela primeira vez, da exposição parisiense de $1867^{9}$. Mas a Exposição Universal de Viena foi a primeira após a mudança do regime, assim como foi a primeira a ser estudada de forma sistemática pelos pedagogos japoneses. Essa visita fez parte do percurso da missão Iwakura, composta de, aproximadamente, cinquenta indivíduos, na maior parte funcionários públicos de alto escalão, e que foi, provavelmente, o esforço mais sistemático de apropriação de saberes estrangeiros do século 19 (Nish, 1998).

\footnotetext{
${ }^{7}$ Sobre o contexto caótico da promulgação de gakusei ver SCHWEBER, Abigail. Imposing education: the establishment of japan's first national education system, 1872-1879. PhD dissertation. Ann Harbor: University of Michigan, 2003.

${ }^{8}$ Sobre este ponto ver GLUCK, Carol. Meiji et la modernité: de l'histoire à la théorie. In: BERLINGUERKÔNO, Noriko, THOMANN, Bernard (eds.). Japon pluriel 8 : la modernité japonaise en perspective. Actes du huitième colloque de la Société Française des Etudes Japonaises. Arles: Picquier, 2011, p. 575-595; p. 583-584.

${ }^{9}$ Ver Hedinger (2011) e Lockyer (2000). 
Tanaka Fujimaro foi o comissário responsável pelo campo da educação. A missão permaneceu a maior parte do tempo nos Estados Unidos e Tanaka passou a admirar a educação americana. Ele entrou em contato com os pedagogos americanos e considerava a educação dos Estados Unidos a mais desenvolvida e o melhor modelo para o Japão. Mas a missão visitou também os principais países europeus, incluindo a exposição de Viena. Tanaka publicou um vasto relatório, em quinze volumes, sobre suas observações na América e na Europa (Tanaka, 1873). Após, outra missão estudou especialmente a exposição de Viena, publicando igualmente um relatório de dois volumes sobre a educação ${ }^{10}$.

As exposições eram também ocasiões para a aquisição de objetos e de literatura estrangeira. Com o zelo de adquirir objetos e livros ao menor custo possível, os comissários desencadearam até mesmo um "negócio japonês", como dizia um editor parisiense ${ }^{11}$. Os japoneses estavam entre os principais interessados nas trocas dos objetos expostos após o encerramento das exposições.

A missão à exposição da Filadélfia, em 1876, foi ainda mais importante. O monbushō enviou uma missão aos Estados Unidos, dirigida por Tanaka, então viceministro da Educação. Entre os comissários figurava também o americano Murray e Tejima Seiichi, um funcionário do Ministério da Educação. A Centennial exhibitions assistiu à primeira exposição escolar japonesa ${ }^{12}$ mas os japoneses estudaram, sobretudo, as representações de outros países, empreenderam várias viagens a diferentes regiões dos Estados Unidos, chegando até o Canadá, bem como participaram de congressos pedagógicos ${ }^{13}$. Observa-se, mais uma vez, relações intensas com os pedagogos norteamericanos e Tanaka, novamente, redigiu um grande relatório (Tanaka, 1877).

A próxima etapa foi a Exposição Universal de 1878. O comissário da seção escolar era Kuki Ryūichi, funcionário do alto escalão do monbushō. Em Paris ele participou dos trabalhos do júri internacional e lhe foi atribuído o título de oficial da instrução pública ${ }^{14}$. Tejima servia também de comissionário em Paris e o Japão se apresentou como um país engajado num processo de institucionalização e reformas. Os visitantes tinham esta impressão, entre outras, pelas traduções de relatórios prussianos, holandeses e franceses ${ }^{15}$. A exposição parisiense ofereceu a possibilidade de se entrar em contato com os pedagogos franceses e, nestas circunstancias, não surpreende que Tejima tenha redigido a nota sobre o Japão no Dictionnaire de pédagogie de Ferdinand Buisson ${ }^{16}$. Após

${ }^{10}$ Okoku hakurankai hôkokusho: kyôiku, Tôkyô, Hakurankai jimukyoku, 1875.

${ }^{11}$ ANF, F17, 9386, Lettre Ch. Larochette à Schaeffer, 25 October 1873.

${ }^{12}$ Ver An outline history of Japanese education, literature and arts: prepared by the Mombusho for the Philadelphia International Exhibition 1876. New York: Appleton, 1876.

${ }^{13}$ Ver The Addresses and Journal of Proceedings of the National Educational Association. Session of the year 1876 in Baltimore, Maryland. Salem, Vatem, 1876; International Conference on Education: Held at Philadelphia, July 17 and 18: in Connection with the International Exhibition of 1876. Washington: Government Printing Office, 1877.

${ }_{15}^{14}$ ANF, F17, 2597, palmas acadêmicas, 1878-1880.

${ }^{15}$ Catalogue des objets envoyés à l'Exposition universelles de Paris (mai 1878) par le Ministère de I'Instruction Publique du Japon. Paris: Imprimerie H. Lutier, 1878; Le Japon à l'Exposition Universelle de 1878, publié sous la direction de la Commission Impériale Japonaise. Paris: Commission Impériale du Japon, 1878. Ver também GALAN, Christian. Le nouveau paradigme éducatif du début de Meiji. Analyse d'une liasse de compositions écrites par des écoliers japonais durant les années 1870. In: HORIUCHI, Annick (ed.). Education au Japon et en Chine: eléments d'histoire. Paris: Les Indes savantes, 2006, p. 2148.

${ }^{16}$ INRP 10469, Tegima, Notice sur le Musée pédagogique de Tokio (Japon).

Hist. Educ. (Online)

Porto Alegre
ก. 41

Set./dez. 2013 p. $213-234$ 
o encerramento da exposição, o Japão recebeu novamente uma boa parte dos materiais dos outros países.

Como os saberes acumulados nas exposições influenciaram a institucionalização da educação japonesa? Tanaka se transformou em um grande admirador da educação americana e, em uma carta dirigida ao diretor do Escritório de Educação de Washington em 1878, elogiou os americanos por terem a melhor representação na exposição de Paris, e afirmou que esperava que a educação dos Estados Unidos influenciasse os países europeus, assim como o Japão ${ }^{17}$. Tanaka tinha uma visão bastante liberal e queria implantar o controle local da educação, como era praticado no outro lado do Pacífico ${ }^{18}$. É o que ele intentou com seu Código educativo - kyōikurei - de 1879, com o qual desejava substituir o gakusei de 1872. Mas a proposta fracassou e Tanaka foi afastado do Ministério da Educação. O Código educativo revisado - kaisei kyōikurei -, de 1880, restabeleceu os pontos centrais de gakusei e incluiu a autoridade central.

Se, por um lado, a tentativa de Tanaka de implantar o controle local da educação não aconteceu, por outro, não foi necessariamente o fracasso da referência americana, pois os discípulos do americano Murray, que era a favor de uma centralização, se impuseram. Somente mais tarde a referência americana tornou-se menos importante, quando novos gestores descobriram as supostas vantagens da educação prussiana (Pittau, 1967).

Juntamente a essas peripécias institucionais, as exposições tiveram outras consequências no Japão. O Museu Pedagógico - kyōiku hakubutsukan - foi criado em Tóquio, em 1877, (Komatsu, 2009) e Tejima tornou-se seu primeiro diretor. Os museus pedagógicos foram criados durante a segunda metade do século 19 em muitos países e serviam como centros de informação, bibliotecas e como pontos de contato entre os níveis nacionais e transnacionais. Murray foi encarregado de adquirir objetos para o novo museu durante sua estada na Filadélfia. Para tanto, ele dispunha de certo valor e negociava com pedagogos, editores e fabricantes. Muitas publicações, mas também objetos maiores como, por exemplo, bancos de escola, foram deixados aos japoneses após a exposição e gratuitamente encaminhados ao referido museu. A maior parte das obras ocidentais da biblioteca do museu era, na verdade, anglo-saxônica (Hashimoto, 1998). O museu pedagógico de Tóquio foi resultado direto da missão à Filadélfia de 1876.

Em suma, os funcionários do alto escalão do Ministério da Educação japonês utilizaram as exposições dos anos 1870 com o objetivo de apropriarem-se dos saberes para a institucionalização de seu sistema de ensino. Mesmo que o caminho que a institucionalização tomou tenha sido seguidamente ambíguo, a referência americana desempenhou o papel principal.

\section{França}

Apesar de a França, dos anos 1870, se encontrar em uma situação política e social completamente diferente da japonesa, observam-se também semelhanças, como a mudança do regime com o final do Segundo Império e os déficits que persistiam na

17 Carta mencionada em NARA, Microfilm M-635, Roll 10, Lettre John Eaton à John D. Philbrick, Washington, 2 septembre 1878.

${ }^{18}$ Ver YUKAWA, Fumihiko. Meiji shoki kyōiku jimu no seiritsu - Tanaka Fujimaro to Meiji juni-nen kyōiku rei. In: Shigaku Zasshi, 121, 6, 2012, p. 1-39.

Hist. Educ. (Online) $\quad$ Porto Alegre

V. 17

ก. 41

Set./dez. 2013

p. $213-234$ 
organização da instrução pública. Não é, então, surpreendente que se constate semelhante comportamento dos especialistas da educação francesa na cena das exposições universais.

O ensino primário francês foi organizado nos anos 1830 (Mayeur, 2004) e, salvo algumas exceções, a educação primária ainda não era gratuita. A igreja católica tinha uma grande influência sobre o ensino e o ensino primário não era nem gratuito, nem obrigatório ou laico. No entanto, a educação era um aspecto chave de um grande debate político que confrontava opiniões progressistas na igreja católica. Como relata, por exemplo, a Liga do Ensino, havia também pressões da sociedade civil de introduzir a obrigação e a gratuidade (Auspitz, 1982).

Neste contexto, a referência ao estrangeiro já havia aparecido como possível remédio aos defeitos franceses. Célestin Hippeau, por exemplo, visitou muitos países e redigiu monografias sobre seus sistemas de educação (Bastos, 2002). Por ocasião da exposição universal de 1867, os países germânicos inspiraram uma parte dos educadores franceses. A Prússia construiu uma escola de campanha no Champ de Mars, amplamente comentada nos meios pedagógicos franceses. A Saxe ${ }^{19}$ construiu um pavilhão no estilo de um templo grego e engendravam-se, principalmente, discursos sobre a superioridade da obrigatoriedade escolar ${ }^{20}$.

Após a mudança de regime, começou uma nova etapa. Observa-se uma verdadeira intervenção republicana na participação francesa nas exposições escolares. Havia um grupo de pedagogos republicanos franceses que procuravam argumentos em sua luta contra os conservadores no contexto do regime repressivo da ordem moral e que se esforçava em adquirir um saber-fazer da gestão dos negócios escolares. O personagem central destes esforços era Ferdinand Buisson. Tendo obtido seu diploma em Filosofia em 1863, ele recusou o juramento a Napoleão III e exilou-se em Neuchâtel, onde desenvolveu seu ponto de vista do protestantismo liberal (Tomei, 2004). Ao voltar à França em 1870, tornou-se inspetor primário em Paris, mas teve que deixar seu cargo em razão das pressões católicas, no final de $1872^{21}$.

O ministro da Instrução Pública, Jules Simon, encarregou Buisson de organizar a exposição escolar francesa na Exposição Universal de Viena de 1873. Buisson tinha a ideia de ampliar sua missão e "estudar as exposições escolares dos outros países e [...] apresentar sobre este assunto um relatório geral”22, proposição foi aceita pelo Ministério. A escolha de Buisson como comissário foi acompanhada de fortes polêmicas. A imprensa católica falava do "niilista" Buisson, do "comunista teórico" e do representante "do ensino laico, materialista e ateu". Em Viena, Buisson representava a França e teve a oportunidade de estudar as exposições escolares de outros países. Buisson fez o circuito dos países germânicos e, após o encerramento da exposição, redigiu um relatório de mais de 350 páginas no qual apresentou o "estado atual da instrução pública" (Buisson,

\footnotetext{
${ }^{19}$ Nota de revisão: Saxe corresponde ao antigo ducado semi-independente da Alemanha, situado no atual Estado de Turíngia, um dos estados federais da Alemanha localizado no centro do país.

${ }^{20}$ Ver CHATEAU, Léon. Enseignement public d'après les documents contenus dans la classe 90 de l'Exposition universelle de 1867. Enseignement primaire et enseignement professionnel, Paris, Lacroix, 1868 e DEFODON, Charles, Promenade à l'Exposition scolaire de 1867. Souvenir de la visite des instituteurs. Paris: Hachette, 1868.

${ }^{21}$ Nota do editor: ver BASTOS, Maria Helena Camara. Método intuitivo e lições de coisas por Ferdinand Buisson. Hist. Educ. [online]. v. 17,n. 39, 2013, p. 231-253.

${ }^{22}$ ANF, F17, 2343C, Letter Ferdinand Buisson to the minister of public instruction, 18 february 1873.
} \begin{tabular}{l|l|l|l|l|l|}
\hline Hist. Educ. (Online) & Porto Alegre & v. 17 & n. 41 & Set./dez. 2013 & p. 213-234
\end{tabular} 
1875). Enviou seu relatório a vários colegas estrangeiros, segundo uma lista feita por ele para o Ministério das Relações Exteriores. Tinha então feito vários conhecidos na capital austríaca e havia conseguido se integrar em uma rede transnacional. Nesta rede estava também John D. Philbrick, superintendente da instrução pública da cidade de Boston e comissário americano na exposição vienense, um personagem que desempenhou um papel primordial nas relações transatlânticas.

Em 1876 Buisson dirigiu novamente uma missão, desta vez à Centennial exhibition da Filadélfia. Mesmo que a França tenha participado desta exposição, não houve exposição escolar francesa, uma vez que a missão tinha o único objetivo de estudar países participantes, em particular os Estados Unidos. Juntamente com Buisson, cinco comissários atravessaram o Atlântico: dois inspetores primários, dois professores do ensino primário público e um professor do ensino primário livre, indicados pela Sociedade dos Professores e Professoras de Ensino Primário do Sena. A comissão estabeleceu sua sede no pavilhão escolar da Pensilvânia, dirigido por James P. Wickersham, superintendente da instrução pública neste local. Como no caso japonês, os especialistas franceses não ficaram somente na exposição: viajaram para diversos Estados e ao Canadá, visitaram instituições escolares e participaram de congressos. Disso resultaram contatos intensos com os grandes nomes da educação americana da época, incluindo, por exemplo, John D. Philbrick. Após seu retorno à França, Buisson e seus colaboradores redigiram um relatório monumental de 700 páginas sobre o ensino americano (Buisson, 1878).

Dois anos mais tarde, por ocasião da Exposição Universal de 1878, os contatos americanos foram convidados para irem à Paris. Philbrick, presidente da exposição escolar americana, então residiu na casa de Buisson, no número 166 do Boulevard Montparnasse ${ }^{23}$. O jogo das premiações honoríficas demonstra a cordialidade das relações entre educadores americanos e pedagogos republicanos franceses: numerosos comissários americanos receberam palmas acadêmicas, Philbrick foi recebido até mesmo pela Legião de Honra e os franceses participantes da missão à Filadélfia foram também premiados com as palmas acadêmicas. A exposição escolar americana correspondeu às expectativas dos republicanos franceses e a entrada estava decorada por três slogans:

$\begin{gathered}\text { "É no governo republicano que se tem necessidade de toda potência da } \\ \text { educação". (M ontesquieu) }\end{gathered}$
"Promote as an object of primary importance institutions for the general
diffusion of knowledge". (Washington)
"A instrução pública é GRATUITA em todos os Estados da União."

${ }^{23}$ Ver DUNTON, Larkin. A Memorial of the Life and Services of John D. Philbrick. Boston: New England Publishing Co., 1887, p. 180. Em NARA, Microfilm M-635, Filme 10, encontram-se várias cartas ao Bureau of Education destinadas a Philbrick em nome de Buisson.

${ }^{24}$ Ver PHILBRICK, John D. Report of John D. Philbrick, LL.D. Superintendent of the Educational Section. In: Reports of the United States Commissioners to the Paris Universal Exposition, 1878. Published under direction of the secretary of state by authority of congress. Washington: Government Printing Office, 1880, v. 1 , p. 87-108; p. 91. 
Um artigo de Emile Levasseur (1878), na Revista Pedagógica, relata muito positivamente a exposição americana e informa que a criação do museu pedagógico foi um resultado direto da exposição de $1878^{25}$. Os americanos confiaram a quase totalidade de sua exposição escolar a esta nova instituição.

Durante a exposição de 1878 Buisson foi promovido a inspetor geral do ensino primário. Sua promoção foi tornada pública em 31 de agosto, quando ele se dirigia aos professores de ensino primário convidados a virem a Paris no contexto das conferências pedagógicas $^{26}$, o que refletia as mudanças políticas. Em seguida, em janeiro de 1879, Buisson tornou-se diretor do ensino primário. Os pedagogos republicanos, que haviam conseguido impor-se no cenário internacional encontraram, então, espaço para as suas proposições no contexto nacional, ou, em outras palavras, o engajamento transnacional Ihes permitiu superar as oposições que encontravam em nível nacional.

$\mathrm{O}$ que os franceses retiveram de seus contatos com os americanos? Em que medida a referência americana influenciou o debate francês sobre a escola obrigatória e gratuita? Se analisamos o relatório de Buisson acerca da exposição da Filadélfia, observamos quatro pontos principais, juntamente com uma grandeza de detalhes bem aprofundados, que categorizam questões administrativas acerca do mobiliário escolar, passando pela pedagogia das matérias ensinadas ${ }^{27}$. O que serve como fio condutor do relatório é a admiração por uma república bem estabelecida, que investe massivamente na educação e a transforma em verdadeiro serviço público. É exatamente esta inspiração republicana que conduziu ao outro lado do Atlântico, à gratuidade e obrigatoriedade escolar. Além do mais, era um Estado que não se envolvia nas questões religiosas e alimentava uma atmosfera de respeito mútuo que fascinou Buisson. Ele apreciou que, embora a forte inspiração protestante, as autoridades não tentavam impor uma religião, devido, principalmente, à variedade de denominações. Buisson observou que esta liberdade das consciências diferia do Estado laico à moda francesa (Buisson, 1878). Mesmo assim, a referência americana reforçou o aumento dos apoiadores da laicidade na França. Os Estados Unidos, único país no qual este aspecto fora suficientemente discutido, conduziu uma solução que difere da maior parte dos países europeus.

Ao lado destes dois pontos integrados no discurso republicano e mais tarde institucionalizados, há também aspectos controversos. Um deles é a coeducação de meninos e meninas que se praticava de forma generalizada nos Estados Unidos. ${ }^{28}$ Buisson explicava a coeducação naquele país pela posição das mulheres na sociedade americana, pois tinham muito mais liberdade do que na Europa. Enquanto ele aceitava, em princípio, a coeducação na escola primária, se opunha com veemência a coeducação para os jovens.

${ }^{25}$ Ver MAJAULT, Joseph. Les origines de I'IPN: le musée pédagogique (1872-1879). Paris: Editions de I'IPN, 1959.

${ }^{26}$ Ver as Conférences pédagogiques faites aux instituteurs primaires venues à Paris pour l'Exposition universelle de 1878. Paris: Hachette, 1878.

${ }^{27}$ Para uma análise mais detalhada do relatório, ver PORTES, Jacques. Une fascination réticente: les EtatsUnis dans l'opinion française. Nancy: Presses universitaires de Nancy, 1990, p. 205-226 e TOMEI, Samuel. Ferdinand Buisson (1841-1932): protestantisme libéral, foi laïque et radical-socialisme, sous la direction de Serge Berstein. Thèse de doctorat, Institut d'études politiques, Paris, 2004. p. 286-293.

${ }^{28} \mathrm{O}$ relatório de Buisson introduziu a noção de coeducação na Europa. Ver KARNAOUCH, Denise. Féminisme et coéducation en Europe avant 1914. In: CLIO. Histoire, Femmes et Sociétés, 18, 2003. p. 21-41.

Hist. Educ. (Online)

Porto Alegre

v. 17

ก. 41

Set./dez. 2013

p. $213-234$ 
Finalmente, Buisson era fascinado pela capacidade da escola americana de aproximar as classes sociais. Nessa escola não havia seleção preliminar e, ao menos na teoria, oferecia a possibilidade a cada aluno de seguir seu percurso escolar em uma high school, mesmo se poucos alunos continuavam até o final. Ele observou que viu crianças burguesas e operárias lado a lado em uma escola pública de Boston (Tomei, 2004) e isto marcou o início, ainda muito discreto, dos debates sobre a escola única na França (Dubois, 2007).

Observemos também que Buisson, ao contrário de Tanaka, não considerava a ideia de dar mais poder às municipalidades. Teoricamente, ele poderia ter pensado em apoiar as municipalidades progressistas contra um ministério nacional conservador. Mesmo assim, as exposições universais dos anos 1870 desempenharam um grande papel ao colocarem em contato os pedagogos dos dois lados do Atlântico e, possivelmente por isso, a escola republicana francesa estabelecida em 1882 tenha comportado uma importante dimensão americana.

\section{Estados Unidos}

Os administradores americanos apareciam como mestres de seus colegas estrangeiros, japoneses e franceses. Denomina-se esta geração de gestores do ensino público de os common school crusaders (Hansot; Tyack, 1982). A partir dos anos 1830, os common school crusaders, como Horace Mann e Henry Barnard, começaram a organizar a instrução pública, com poder para os Estados federados e sem uma regulação em nível nacional. Nos anos 1870 os representantes mais famosos eram, provavelmente, os mencionados Philbrick e Wickersham, aos quais se podem acrescentar personagens como Birdsey G. Northrop, secretário do Connecticut Board of Education, ou Henry Kiddle, superintendente das escolas públicas da cidade de Nova lorque. Estes personagens eram animados por sua fé protestante e seus valores burgueses, capitalistas e republicanos e eram eles que os especialistas japoneses e franceses encontravam na América. Estes americanos sabiam exatamente como os japoneses e os franceses se referiam ao que haviam observado nos Estados Unidos e traduziram, orgulhosamente, os relatórios que elogiavam suas instituições ${ }^{29}$.

Nos anos 1870 a instrução primária era gratuita e obrigatória, mesmo se o absenteísmo continuasse sendo um problema. $O$ ensino primário, que era um dos pilares da república americana (Kaestle, 1983), assistiu a um período de transformações a partir dos anos 1870, dentre as quais uma mudança na geração de gestores da instrução pública nos Estados Unidos. Os common school crusaders foram substituídos por uma nova geração, os administrative progressives. Cabe destacar que após a guerra civil, os Estados Unidos se tornavam uma nação moderna e, de um país rural, se desenvolvia uma sociedade industrial e urbana, com o desejo de tornar o ensino mais prático, de não oferecer somente uma cultura geral, mas também conhecimentos que os jovens pudessem aplicar no mundo do trabalho.

À exceção de algumas raras instituições especializadas, o ensino técnico era praticamente inexistente no outro lado do Atlântico. Os Estados Unidos eram um país de job culture oposto à school culture, para usar as expressões de Peter Lundgreen (1990).

\footnotetext{
${ }^{29}$ Ver, por exemplo: BUISSON, Ferdinand. American education as described by the French commission to the international exhibition of 1876. Washington: Government Printing Office, 1879.
Hist. Educ. (Online)
Porto Alegre
v. 17
n. 41
Set./dez. 2013
p. $213-234$ 
O que significa que o sistema escolar não oferecia conhecimentos práticos que, entretanto, eram desenvolvidos na prática, nas oficinas. Ainda nos anos 1870 o ensino técnico era percebido como algo especificamente europeu.

O interesse pela dimensão prática do ensino começaram com os progressos que concerniam mais precisamente ao ensino superior e médio. John D. Runkle era o presidente do Massachusetts Institute of Technology, na Filadélfia. Runkle passeava pelos palácios da exposição quando descobriu a representação das escolas politécnicas russas de Moscou e de São Petersburgo. Como expressou o historiador Lawrence Arthur Cremin (1961), a educação americana desde então não foi mais a mesma.

O que aconteceu com Runkle? Ele tinha se perguntado como organizar a formação prática dos futuros engenheiros, se a instrução nos laboratórios era até então desorganizada e ineficaz. Os pedagogos russos haviam inventado um novo método de como ensinar aos estudantes procedimentos passo a passo em laboratórios especialmente criados para fins pedagógicos. Os gestores russos apresentavam as escolas politécnicas bem equipadas e metodologicamente inovadoras com certo orgulho nas exposições dos anos 1870. Runkle (1876) descobriu este método na Filadélfia e ficou impressionado porque tal método oferecia uma solução para suas próprias preocupações. Seguiu-se, então, um vasto trabalho de apropriação do método russo, como foi denominado doravante na América. Ele estabeleceu contatos intensos com os responsáveis russos e mesmo tornou-se um membro honorário do Conselho de Administração da Escola Politécnica de Moscou. Quando da exposição universal de 1878, Runkle foi à Europa e visitou as principais instituições politécnicas francesas e alemãs.

Outro visitante da exposição da Filadélfia foi Calvin M. Woodward, professor da Washington University, situada na cidade de Saint-Louis, e mais interessado no ensino médio (Knoll, 1988). Woodward (1887) também estava impressionado pelo que ele chamava de clareza e lógica do método empregado nas escolas russas e foi à Europa por ocasião da International Health Exhibition de Londres, em 1884, para obter procedimentos que pudessem ser uma inspiração aos seus próprios planos.

Os dois casos, de Runkle e Woodward, são muito bem estudados. Sua função para a transferência de saberes já era percebida por seus contemporâneos, mas um número bem maior de pedagogos americanos utilizaram as exposições universais para informarse sobre o ensino técnico europeu, daí que se deve estabelecer um discurso muito mais vasto.

Charles B. Stetson, promotor de um ensino mais prático, considerou que o ensino da noção de cultura geral não era mais suficiente no momento em que os Estados Unidos tornava-se um país de produção capitalista em grande escala. Após a Exposição Universal de Viena, Stetson argumentou que o grande exemplo educativo era a Europa e redigiu um prefácio para a tradução de um relatório austríaco sobre o ensino da arte (Langl, 1875). Stetson visitou também as exposições da Filadélfia e de Paris, em 1878, com o objetivo de se informar sobre a instrução técnica ${ }^{30}$.

\footnotetext{
${ }^{30}$ Ver STETSON, C. B. Popular instruction in elementary drawing. In: United States Centennial Commission. International Exhibition, 1876. Reports and Awards. Volume 8. Groups 20VIII-20XVI, and Collective Exhibits. Washington: Government Printing Office, 1880, p. 275-307 e JEWETT, Eliot C. Manual training schools represented at the exposition. Reports of the United States Commissioners to the Paris Universal Exposition, 1878. Published Under Direction of the Secretary of State by Authority of Congress. Washington D.C.: Government Printing Office, 1880, v. 2, p. 383-415. \begin{tabular}{|l|l|l|r|}
\hline Hist. Educ. (Online) & Porto Alegre & v. 17 & n. 41 \\
\hline
\end{tabular} \begin{tabular}{l|l} 
n. $41 \quad$ Set./dez. 2013
\end{tabular} p. 213-234
} 
Paralelamente, o inglês Walter Smith, que frequentava regularmente as exposições, foi recrutado como diretor da nova Massachusetts Normal Art School em Boston, pela iniciativa de Philbrick e mesmo os defensores da escola pública começavam então a ver a utilidade do ensino técnico. Após o fechamento da exposição de 1873, Philbrick visitou Praga, Liverpool, Londres, Paris, Bruxelas, assim como as principais cidades alemãs, com um interesse particular pelo ensino técnico (Dunton, 1887). O mesmo se sucedeu com Wickersham (1886), que visitou vários países europeus em 1878.

No contexto das exposições universais dos anos 1870, observa-se um intenso trabalho de apropriação por parte dos pedagogos americanos interessados no ensino técnico europeu. Como o saber acumulado através das exposições mudou a educação americana? No Massachusetts Institute of Technology Runkle procedeu imediatamente, instalando um laboratório adaptado ao método russo. Evidentemente este método foi copiado por outros. Além do nível superior do ensino técnico, as mudanças afetaram o ensino secundário com a criação do Manual training highschools, ou seja, highschools que dispunham de oficinas e dedicavam uma parte importante do plano de estudos ao trabalho manual. Woodward estabeleceu seu Manual training highschool em Saint-Louis e um bom número de instituições similares foi criado, por exemplo, na Filadélfia e em Chicago.

O elemento prático se desenvolvia como um caráter paradigmático da nova educação americana e dizia respeito também ao ensino primário. Os pedagogos americanos refutavam a ideia - uma ideia europeia, segundo eles - de que o trabalho manual servia, exclusivamente, para a formação de futuros operários. Todavia, a ideia americana, como o expressava Woodward, era a de uma educação mais completa para todos os alunos, uma educação que combinasse elementos de cultura geral e práticas (Woodward, 1887). A existência de classes sociais não era aceitável na ideologia individualista dos Estados Unidos e almejava-se oferecer as mesmas chances a todas as crianças.

O ensino do desenho foi fortemente difundido. Em Massachusetts, todas as cidades de mais de 2.000 habitantes deviam oferecer cursos de ensino de desenho industrial. Encontram-se os mesmos discursos na Europa, por exemplo, na França, mais forte que nos Estados Unidos, com mudanças mais pronunciadas. Imagem da Europa, mas não necessariamente uma realidade.

A longo prazo os projetos pedagogicamente nobres de oferecer uma educação mais completa a todos os alunos se transformaram em esforços de melhor classificá-los, em nome da eficácia, e em melhor guiá-los às carreiras profissionais preestabelecidas. Tal concepção ligava-se ao desenvolvimento da psicologia infantil.

Em resumo, ao mesmo tempo em que os defensores da escola pública eram orgulhosamente solicitados pelos seus pares japoneses e franceses que estavam interessados em suas realizações, uma nova forma de educação se estabelecia lentamente nos Estados Unidos. A transferência de algumas características europeias, no contexto das exposições universais, tornou a educação americana mais prática, assim como conduziu a uma reformulação do ensino nos Estados Unidos. 


\section{Alemanha}

Durante os anos 1870 não há uma equipe alemã de especialistas pedagógicos a frequentar as exposições universais, como foi possível observar com os três países estudados antes. Várias causas explicam esta situação. Há, primeiramente, uma participação irregular da Alemanha nas exposições universais (Fuchs, 1999). A Alemanha participou em Viena, mas absteve-se das exposições parisienses, salvo em 1900, fazendo, todavia, intenso esforço para preparar exposições escolares muito completas, como em Chicago e em Saint-Louis. Outra razão é que o país alemão foi o primeiro a aperfeiçoar uma oferta de escola primária. Na metade do século 19, no região do Saxe, tinha-se a taxa de alfabetização mais elevada do mundo (Moderow, 2007).

A institucionalização da escola primária estava bem concluída, mas havia a necessidade imediata que demandava a busca de um saber estrangeiro aplicável ao contexto germânico. Isto se combina com um chauvinismo que se expressa após a fundação do Império alemão em 1871. Consequentemente, o número de relatórios pedagógicos redigidos após as exposições internacionais é relativamente baixo, se comparados à massa de literatura publicada na França e nos Estados Unidos ${ }^{31}$. Esta ausência relativa da Alemanha surpreende um pouco, uma vez que o modelo germânico aparecia como referência última. Os contatos com a Alemanha deviam, assim, tomar outros caminhos para além das exposições universais.

Inicialmente os alemães se interessavam somente por questões muito especializadas. Era o caso da questão dos bancos escolares, abordada pelo oftalmologista de Breslau, Hermann Cohn. Ele frequentou as exposições de 1867, 1873 e 1878 , estudou os bancos de escola e outros aspectos de higiene escolar ${ }^{32}$.

Um dos raros alemães a se interessar pela educação na Exposição Universal de 1889 foi Maximilian Weigert. Este grande burguês berlinense, fabricante têxtil, engajou-se pela municipalidade da capital alemã onde trabalhava, entre outros, em um comitê de educação. O magistrado de Berlin o enviou a Paris para estudar a educação na exposição universal na capital francesa e as suas observações foram publicadas num relatório no qual consta uma descrição bastante completa do sistema de ensino público francês (Weigert, 1890).

Como empreendedor, ele se concentrou, principalmente, nas questões relativas ao ensino técnico e ao trabalho manual. Sua avaliação do que via na França era muito positiva e estimava que a Alemanha deveria renunciar ao seu chauvinismo e aprender coisas do exterior, em particular, da França. Ele falava da escola republicana como um progresso substancial diante do sistema prussiano. Em sua conclusão, Weigert enumerou três pontos que julgava deviam ser adaptados na Prússia: o caráter laico das escolas francesas; a gratuidade das escolas superiores enquanto que semelhantes instituições prussianas eram pagas e, em terceiro lugar, apreciava que a maior parte das escolas

\footnotetext{
${ }^{31}$ Uma introdução às diferentes publicações se encontra em DITTRICH, Klaus. Deutsche Berichterstattung über die Bildungssektionen der Weltausstellungen des 19. Jahrhunderts. Ein Literaturüberblick. In: KESPER-BIERMANN, Sylvia, WISCHMEYER, Johannes (eds.). Transnationale Bildungsraüme. Wissenstransfers im Schul- und Hochschulsektor in der Moderne. Göttingen: Vandenhoeck \& Ruprecht, 2012 (a ser publicado).

${ }^{32}$ Ver COHN, Hermann. Die Schulhäuser auf der Pariser Weltausstellung, vom hygienischen Standpunkte beurtheilt. In: Berliner klinische Wochenschrift, 4, 41, 1867, p. 424-428; COHN, Hermann. Die Schulhäuser und Schultische auf der Wiener Weltausstellung: eine augenärztliche Kritik. Breslau: Morgenstern, 1873; COHN, Hermann. Die Schulhygiene auf der Pariser Weltausstellung, 1878. Breslau: Morgenstern, 1879. 
dispunha de oficinas para o trabalho manual. Weigert colocou em destaque seus interesses como empreendedor e seu pertencimento a uma minoria religiosa como judeu. Onze anos mais tarde, por ocasião da exposição universal de 1900, alguns pedagogos alemães se interessaram também pelas realizações francesas. W. Kahle apresentou aos seus leitores uma avaliação positiva do ensino primário francês. Segundo este professor do seminário da pequena cidade prussiana de Köthen, a França era superada pela Alemanha em muitos campos ${ }^{33}$.

O caso mais sistemático de apropriação de saberes estrangeiros por meio das exposições é, provavelmente, o de Alwin Pabst, diretor da Deutsche Lehrerbildungsanstalt für Knabenhandarbeit, que se pode traduzir como escola normal para o trabalho manual dos meninos. Esta instituição foi criada em Leipzig, em 1887, e em 1900 Pabst visitou a Exposição Universal de Paris. Em seu relatório descreveu os parisienses, e os franceses em geral, detalhadamente. Descreveu, ainda, como passava horas na exposição estudando as ferramentas de trabalho e os trabalhos de alunos que estavam apresentados (Pabst, 1900). Em 1904 Pabst atravessou o Atlântico para ir à exposição universal de Saint-Louis e legitimava sua viagem pelo alto nível de ensino do trabalho manual no outro lado do Atlântico. Segundo ele a Alemanha devia aproveitar as experiências americanas ${ }^{34}$. Do outro lado do Atlântico Pabst teve um vasto programa de visitas a escolas, bem como encontrou todos os grandes pedagogos americanos ligados à nova educação. Juntamente com uma monografia, publicou vinte artigos em diversas revistas pedagógicas alemãs, nos quais salientou, principalmente, o valor do trabalho manual para a educação geral. Recusava, então, uma visão que via no trabalho manual uma pura preparação ao trabalho dirigida aos futuros operários. Pabst citava o historiador de Leipzig, Karl Lamprecht, com quem havia atravessado o Atlântico, e que considerava que a troca cultural era uma força chave no desenvolvimento da civilização.

Juntamente com Pabst, uma comissão do Ministério do Comércio prussiano foi também enviada à Saint-Louis ${ }^{35}$. A maior parte dos comissários se ocupou das questões de ensino técnico superior, mas alguns trataram também das questões de ensino primário. Eles ainda fizeram uma avaliação positiva da educação americana e apreciaram, sobretudo, seu caráter prático.

Em geral, observa-se um interesse dos pedagogos alemães nas recentes realizações americanas e francesas. Os atores deste discurso estavam à margem do discurso dominante e não dispunham de um grande poder de decisão a fim de terem uma influência sobre as instituições estatais. Seguidamente eles pertenciam a minorias religiosas, levando em conta que Cohn e Weigert eram judeus, e utilizaram suas viagens às exposições para tentar aproveitá-las em seu contexto nacional, em especial para desenvolver o ensino técnico, uma vez que estavam mais próximos da economia.

Pabst não conseguiu mudar fundamentalmente o desprezo pelo trabalho manual na Alemanha. Ainda assim, tentou institucionalizar alguns elementos em seu seminário de Leipzig, mas não conseguiu desenvolvê-lo enquanto escola modelo da nova educação, assim como não recebeu suficiente apoio do Ministério saxônico. O neologismo

\footnotetext{
${ }^{33}$ Ver KAHLE, W. Ein Gang durch die pädagogische Abteilung der Pariser Weltausstellung. In: Neue Bahnen, 12, 3, 1901, p. 177-186; 12, 4, 1901, p. 238-246.

${ }^{34}$ Ver Nachrichten. In: Blätter für Knabenhandarbeit, 18, 3, 1904, p. 63.

${ }^{35}$ Ver Reiseberichte über Nord-Amerika. Erstattet von Kommissaren des Königlich Preußischen Ministers für Handel und Gewerbe. Berlin: Moeser, 1906. Hist. Educ (Online) $\quad$ Porto Alegre v. 17 ก. 41 Set./dez. 2013 p. $213-234$
} 
"manualismo" foi até mesmo criado para combater uma expansão do trabalho manual. A longo prazo, os pedagogos, a exemplo de Pabst, prepararam a conjuntura da Reformpädagogik na Alemanha de entre-guerras.

Em resumo, alguns especialistas alemães tentaram tornar o ensino alemão mais prático referindo-se às experiências americanas e francesas.

\section{Conclusão}

Tentamos mostrar que as exposições universais desempenharam um papel fundamental para a circulação transnacional de saberes pedagógicos durante a segunda metade do século $19^{36}$. Foram palcos para o contato com os pares estrangeiros, para a coleta de informações e para a aquisição de objetos e literatura. As exposições, como meio de comunicação, combinaram-se com as visitas das missões, com a redação e a circulação dos relatórios, com os museus pedagógicos e os congressos internacionais. Os atores iam às exposições por razões bem específicas e, como se viu, uma de suas preocupações era o desenvolvimento do ensino em seus próprios contextos. Seu enraizamento nos debates nacionais diferiu, consideravelmente, de país a país.

Percebe-se uma verdadeira rede américo-franco-japonesa ativa nas exposições dos anos $1870^{37}$. Esta rede se compunha dos defensores da escola pública americana, dos pedagogos republicanos franceses, assim como de funcionários japoneses. Os pedagogos alemães se mantiveram distanciados desta rede, que comportou também um curioso elemento social. Enquanto os americanos eram mais velhos e praticamente em fim de carreira, os japoneses tinham em torno de trinta anos. Os franceses tinham idades diversas, mas Buisson possuía somente trinta e cinco anos no momento de sua passagem pela Filadélfia. $O$ que surpreende é a religião protestante dos atores e mesmo os japoneses consideravam o protestantismo como a religião mais civilizada. A rede se dissolveu com a morte dos defensores da escola pública e a institucionalização progressiva da oferta da escola em seus respectivos contextos.

No Japão, as missões às exposições ajudaram na primeira fase de construção de um sistema escolar. Na França, as exposições ofereceram uma possibilidade aos reformadores de prepararem a escola republicana. Nos Estados Unidos, elas ofereceram oportunidades aos pedagogos americanos de encontrarem soluções para reforçar o aspecto prático da educação. Na Alemanha, a visita às exposições e a referência ao exterior eram uma estratégia de subverter o modelo estabelecido, ou seja, a comparação das apropriações permite visualizar concentrações de reformas em uma perspectiva global. Os anos 1870 aparecem como um momento crucial para a institucionalização da escola primária e parece ter sido um momento em que se podia aprender com 0 estrangeiro $^{38}$. A circulação de saberes era importante, mas, após, os modelos nacionais tomaram caminhos diferentes. Observa-se a inexistência de homogeneização, embora algumas características a partir daquele momento fossem universalmente aceitas. Isto

${ }^{36}$ Ver NÓVOA, Antonio M. S. da. La construction du 'modèle scolaire' dans l'Europe du Sud-Ouest (Espagne, France, Portugal): des années 1860 aux années 1920, sous la direction de Jean-Noël Luc. Thèse de doctorat, Paris IV, 2006, p. 237-292.

${ }^{37}$ Sobre as redes educativas ver FUCHS, Eckhardt. Networks and the history of education. In: Paedagogica Historica, 43, 2, 2007. p. 185-197.

${ }^{38}$ Ver DREWEK, Peter; FUCHS, Eckhardt; ZIMMER-MÜLLER, Michael. Internationale Rezeption in pädagogischen Zeitschriften im deutsch-amerikanischen Vergleich 1871-1945/50. Bestandsverzeichnis. Berlin: Bibliothek für Bildungsgeschichtliche Forschung, 2010, p. 41-42.
Hist. Educ. (Online)
Porto Alegre
v. 17
n. 41
Set./dez. 2013
p. $213-234$ 
demonstra também que o que conta na análise da transferência é o contexto de recepção.

Mais tarde, nas exposições universais em torno de 1900, a representação das realizações tomou a frente. Tejima e Kuki tornaram-se grandes mandarins. Tejima, como presidente do principal Colégio Técnico do Japão, compareceu às exposições de Chicago e Saint-Louis como comissário imperial, logo, não para aprender algo, mas para colocar em cena as especificidades nipônicas. Kuki tornou-se o presidente do Museu Imperial Japonês - Teishitsu hakubutsukan - e seu prefácio a uma história da arte japonesa para a exposição de 1900 vangloria: "o Japão é como o parque público mais pitoresco e mais variado do universo" ${ }^{39}$. Da parte francesa, o reitor da academia de Lyon, Gabriel Compayré, no discurso ao Congresso Internacional de Ensino Primário de 1900, enalteceu a escola republicana como a "concepção verdadeira" e "universal" da escola que se difundirá cedo ou tarde no mundo inteiro (Doliveux, 1900, p. 112). Os pedagogos americanos apresentaram seu modelo prático da nova educação como a encarnação do espírito americano (Butler, 1900). Seguidamente escondia-se que suas institucionalizações eram o resultado de transferências e dava-se origem à competição entre os modelos escolares, parte integral da competição das sociedades imperiais analisadas por Christophe Charle (2001).

\section{Referências}

An outline history of Japanese education, literature and arts: prepared by the Mombusho for the Philadelphia International Exhibition 1876. New York: Appleton, 1876.

AUSPITZ, Katherine. The radical bourgeoisie: la ligue de l'enseignement and the origins of the Third Republic, 1866-1885. London: Cambridge University Press, 1982.

BASTOS, Maria Helena Camara. Leituras da ilustração brasileira: Célestin Hippeau (18031883). In: Revista Brasileira de História da Educação, v. 3, n. 1, 2002, p. 67-112.

BREEN, John. The imperial oath of april 1868: ritual, politics, and power in the restoration. Monumenta Nipponica, 51, 4, 1996. p. 407-429.

BUISSON, Ferdinand. American education as described by the French commission to the International exhibition of 1876. Washington: Government Printing Office, 1879.

BUISSON, Ferdinand. Rapport sur l'instruction primaire à l'exposition universelle de Vienne en 1873. Paris: Imprimerie Nationale, 1875.

BUISSON, Ferdinand. Rapport sur l'instruction primaire à l'exposition universelle de Philadelphie en 1876. Paris: Imprimerie Nationale, 1878.

BUTLER, Nicholas Murray (ed.). Education in the United States. Albany: Lyon, 1900.

Catalogue des objets envoyés à l'Exposition universelles de Paris (mai 1878) par le Ministère de l'Instruction Publique du Japon. Paris: Imprimerie H. Lutier, 1878; Le Japon à I'Exposition Universelle de 1878, publié sous la direction de la Commission Impériale Japonaise. Paris: Commission Impériale du Japon, 1878.

\footnotetext{
${ }^{39}$ Ver Histoire de l'art du Japon. Paris: Maurice de Brunoff, 1900, p. XII.

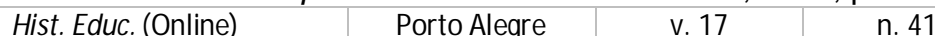

\begin{tabular}{l|l|l|l}
\hline 41 & Set./dez. 2013 & p. 213-234 \\
\hline
\end{tabular}
} 
CHARLE, Christophe. La crise des sociétés impériales: Allemagne, France, GrandeBretagne, 1900-1940. Essai d'histoire sociale compare. Paris: Seuil, 2001.

CHATEAU, Léon. Enseignement public d'après les documents contenus dans la classe 90 de l'exposition universelle de 1867: enseignement primaire et enseignement professionnel. Paris: Lacroix, 1868.

COHN, Hermann. Die Schulhäuser auf der Pariser Weltausstellung, vom hygienischen Standpunkte beurtheilt. In: Berliner klinische Wochenschrift, 4, 41, 1867, p. 424-428.

COHN, Hermann. Die Schulhäuser und Schultische auf der Wiener Weltausstellung: eine augenärztliche Kritik. Breslau: Morgenstern, 1873.

COHN, Hermann. Die Schulhygiene auf der Pariser Weltausstellung, 1878. Breslau: Morgenstern, 1879.

Conférences pédagogiques faites aux instituteurs primaires venues à Paris pour l'Exposition universelle de 1878. Paris: Hachette, 1878.

CREMIN, Lawrence Arthur. The transformation of the school: progressivism in American education, 1876-1957. New York: Knopf, 1961.

DEFODON, Charles, Promenade à l'exposition scolaire de 1867: souvenir de la visite des instituteurs. Paris: Hachette, 1868.

DITTRICH, Klaus. Appropriation, representation and cooperation as transnational practices: the example of Ferdinand Buisson. In: LÖHR, Isabella; WENZLHUEMER, Roland (eds.). The nation state and beyond: governing globalization processes in the nineteenth and early twentieth century. Heidelberg/New York: Springer, 2012 (no prelo).

DITTRICH, Klaus. Deutsche Berichterstattung über die Bildungssektionen der Weltausstellungen des 19. Jahrhunderts. Ein Literaturüberblick. In: KESPER-BIERMANN, Sylvia, WISCHMEYER, Johannes (eds.). Transnationale Bildungsra $\square$ ume: Wissenstransfers im Schul-und Hochschulsektor in der Moderne. Göttingen: Vandenhoeck \& Ruprecht, 2012 (no prelo).

DOLIVEUX, Henri. Le Congrès international de l'enseignement primaire. Paris: C. Delagrave, 1900. p. 112.

DREWEK, Peter; FUCHS, Eckhardt; ZIMMER-MÜLLER, Michael. Internationale Rezeption in pädagogischen Zeitschriften im deutsch-amerikanischen Vergleich 1871-1945/50. Bestandsverzeichnis. Berlin: Bibliothek für Bildungsgeschichtliche Forschung, 2010.

DUBOIS, Patrick. Figures de l'école juste et politique scolaire dans les années fondatrices de la Troisième République. In: Revue française de pédagogie, n. 159, 2007, p. 13-21.

DUKE, Benjamin C. The history of modern japanese education: constructing the national school system, 1872-1890. New Brunswick: Rutgers University Press, 2009.

DUNTON, Larkin. A memorial of the life and services of John D. Philbrick. Boston: New England Publishing Co., 1887.

ESPAGNE, Michel. Les transferts culturels franco-allemands. Paris: PUF, 1999. 
FUCHS, Eckhardt. Das Deutsche Reich auf den Weltausstellungen vor dem Ersten Weltkrieg. In: Comparativ, 9, 5/6, 1999, p. 61-88.

FUCHS, Eckhardt. Networks and the history of education. In: Paedagogica Historica, 43, 2, 2007, p. 185-197.

GALAN, Christian. Le nouveau paradigme éducatif du début de Meiji. Analyse d'une liasse de compositions écrites par des écoliers japonais durant les années 1870. In: HORIUCHI, Annick (ed.). Education au Japon et en Chine: eléments d'histoire. Paris: Les Indes Savantes, 2006, p. 21-48.

GLUCK, Carol. Meiji et la modernité: de l'histoire à la théorie. In: BERLINGUER-KÔNO, Noriko, THOMANN, Bernard (eds.). Japon pluriel 8: la modernité japonaise en perspective. Actes du huitième colloque de la Société Française des Études Japonaises. Arles: Picquier, 2011, p. 575-595.

GREENHALGH, Paul. Ephemeral vistas: the expositions universelles, great exhibitions and world's fairs, 1851-1939. Manchester: Manchester University Press, 1988.

HASHIMOTO, Miho. Meiji shoki ni okeru Amerika kyōiku jōhō juyō no kenkyū. Tōkyō: Kazama Shobō, 1998.

HEDINGER, Daniel. Im Wettstreit mit dem Westen: Japans Zeitalter der Ausstellungen 1854-1941. Frankfurt am Main: Campus Verlag, 2011.

HERREN, Madeleine. Hintertüren zur Macht. Internationalismus und modernisierungsorientierte Außenpolitik in Belgien, der Schweiz und den USA 1865-1914. München: Oldenbourg, 2000.

Histoire de l'art du Japon. Paris: Maurice de Brunoff, 1900. p. XII.

JEWETT, Eliot C. Manual training schools represented at the exposition. Reports of the United States Commissioners to the Paris Universal Exposition, 1878. Published Under Direction of the Secretary of State by Authority of Congress. Washington D.C.: Government Printing Office, 1880, v. 2, p. 383-415.

KAESTLE, Carl F. Pillars of the republic: common schools and American society, 17801860. New York: Hill and Wang, 1983.

KAHLE, W. Ein Gang durch die pädagogische Abteilung der Pariser Weltausstellung. In: Neue Bahnen, 12, 3, 1901, p. 177-186; 12, 4, 1901, p. 238-246.

KARNAOUCH, Denise. Féminisme et coéducation en Europe avant 1914. In: CLIO. Histoire, Femmes et Sociétés, 18, 2003. p. 21-41.

KNOLL, M. Calvin M. Woodward und die Anfänge der Projektmethode. Ein Kapitel aus der amerikanischen Erziehungsgeschichte, 1876-1900. In: Zeitschrift für Pädagogik, 32, 1988, p. 501-517.

KOMATSU, Kayoko. Formation and transformation of education in Japan through exhibitions: focused on the educational museum founded in 1877. In: LAWN, Martin (ed.). Modelling the future: exhibitions and the materiality of education. Oxford: Symposium Books, 2009, p. 73-86. 
KROKER, Evelyn. Die Weltausstellungen im 19. Jahrhundert: industrieller Leistungsnachweis, Konkurrenzverhalten und Kommunikationsfunktion unter Berücksichtigung der Montanindustrie des Ruhrgebietes zwischen 1851 und 1880. Göttingen: Vandenhoeck \& Ruprecht, 1975.

KUHLMANN, Moysés Jr. As grandes festas didáticas: a educação brasileira e as exposições internacionais (1862-1922). São Paulo: USP, 1996. Tese (doutorado em Educação). Universidade de São Paulo, Faculdade de Filosofia, Letras e Ciências Humanas.

LANGL, Joseph. Modern art education: its practical and aesthetic character educationally considered. Being Part of the Austrian Official Report on the Vienna World's Fair of 1873. Translated with note by S. R. Koehler. With an Introduction by Charles B. Stetson. Boston: L. Prang, 1875.

LAWN, Martin (ed.). Modelling the future: exhibitions and the materiality of education. Oxford: Symposium Books, 2009.

LEVASSEUR, Emile. L'Exposition scolaire des Etats-Unis. In: Revue pédagogique, II, 1878.

LINGELBACH, Gabriele. Erträge und Grenzen zweier Ansätze: Kulturtransfer und Vergleich am Beispiel der französischen und amerikanischen Geschichtswissenschaft während des 19. Jahrhunderts. In: CONRAD, Christoph; CONRAD, Sebastian (eds.). Die Nation schreiben: Geschichtswissenschaft im internationalen Vergleich. Göttingen: Vandenhoeck \& Ruprecht, 2002, p. 333-359.

LOCKYER, Angus. Japan at the exhibition, 1867-1970. PhD dissertation, Stanford University, 2000.

LUNDGREEN, Peter. Engineering education in Europe and the USA, 1750-1930: the rise to dominance of school culture and the engineering professions. In: Annals of Science, 47, 1, 1990, p. 33-75.

MAJAULT, Joseph. Les origines de l'IPN: le musée pédagogique (1872-1879). Paris: Editions de l'IPN, 1959.

MAYEUR, Françoise. Histoire générale de l'enseignement et de l'éducation en France. Tome III, De la Révolution à l'École républicaine, 1789-1930. Paris: Perrin, 2004.

MODEROW, Hans-Martin. Volksschule zwischen Staat und Kirche: das Beispiel Sachsen im 18. und 19. Jahrhundert. Köln et al., Böhlau, 2007.

$\mathrm{NISH}$, lan (ed.). The Iwakura mission in America and Europe: a new assessment. Richmond: Japan Library, 1998.

NÓVOA, Antonio M. S. da. La construction du modèle scolaire dans l'Europe du SudOuest (Espagne, France, Portugal): des années 1860 aux années 1920, sous la direction de Jean-Noël Luc, thèse de doctorat, Paris IV, 2006.

Okoku hakurankai hôkokusho: kyôiku, Tôkyô, Hakurankai jimukyoku, 1875.

PABST, Alwin. Der Handfertigkeitsunterricht auf der Pariser Weltausstellung. Leipzig: Frankenstein und Wagner, 1900. 
PHILBRICK, John D. Report of John D. Philbrick, LL.D. Superintendent of the Educational Section. In Reports of the United States Commissioners to the Paris Universal Exposition, 1878. Published under direction of the secretary of state by authority of congress. Washington: Government Printing Office, 1880, v. 1.

PITTAU, Joseph. Political thought in early Meiji Japan, 1868-1889. Cambridge: Harvard University Press, 1967.

PORTES, Jacques. Une fascination réticente: les Etats-Unis dans I'opinion française. Nancy: Presses universitaires de Nancy, 1990.

Reiseberichte über Nord-Amerika. Erstattet von Kommissaren des Königlich Preußischen Ministers für Handel und Gewerbe. Berlin: Moeser, 1906.

RUNKLE, John Daniel. The russian system of shop-work instruction for engineers and machinists. Boston: Kingman, 1876.

SCHRIEWER, Jürgen. Multiple internationalities: the emergence of a world-level ideology and the persistence of idiosyncratic world-views. In: CHARLE, Christophe; SCHRIEWER, Jürgen; WAGNER, Peter (eds.). Transnational intellectual networks: forms of academic knowledge and the search for cultural identities. Frankfurt am Main et al: Campus-Verlag, 2004, p. 473-533.

SCHWEBER, Abigail. Imposing education: the establishment of japan's first national education system, 1872-1879. PhD dissertation. Ann Harbor: University of Michigan, 2003.

STETSON, C. B. Popular instruction in elementary drawing. In: United States Centennial Commission. International Exhibition, 1876. Reports and Awards. v. 8. Groups XXVIIIXXXVI, and Collective Exhibits. Washington: Government Printing Office, 1880.

TANAKA, Fujimaro. Beikoku hyakunenki hakurankai kyōiku hōkoku. Tôkyô: Monbushô, 1877.

TANAKA, Fujimaro. Monbushō Riji Kōtei. Tôkyô: Monbushō, 1873.

The Addresses and Journal of Proceedings of the National Educational Association. Session of the year 1876 in Baltimore, Maryland. Salem, Vatem, 1876; International Conference on Education: Held at Philadelphia, July 17 and 18: in Connection with the International Exhibition of 1876. Washington: Government Printing Office, 1877.

TOMEI, Samuel. Ferdinand Buisson (1841-1932): protestantisme libéral, foi laïque et radical-socialisme, sous la direction de Serge Berstein. Thèse de doctorat, Institut d'études politiques, Paris, 2004.

TYACK, David; HANSOT, Elisabeth. Managers of virtue: public school leadership in America, 1820-1980. New York: Basic Books, 1982.

WEIGERT, Max. Die Volksschule und der gewerbliche Unterricht in Frankreich: Mit besonderer Berücksichtigung des Schulwesens von Paris. Zweite vermehrte Ausgabe. Berlin: Simion, 1890.

WICKERSHAM, James Pyle. A history of education in Pennsylvania, private and public, elementary and higher: from the time the Swedes settled on the Delaware to the present day. Lancaster: Inquirer Publishing Company, 1886. 
WOODWARD, C. M. The manual training school, comprising a full statement of its aims, methods, and results, with figured drawings of shop exercises in woods and metals. Boston: D. C. Heath \& Co., 1887.

YOSHIIE, Sadao. David Murray, Superintendent of Educational Affairs in Japan: his views on education and his influences in japan and in the United States. PhD thesis, State University of New York at Buffalo, 1992.

YOUNG, Paul. Globalization and the great exhibition: the victorian new world order. New York: Palgrave Macmillan, 2009.

YUKAWA, Fumihiko. Meiji shoki kyōiku jimu no seiritsu - Tanaka Fujimaro to Meiji juni-nen kyōiku rei. In: Shigaku Zasshi, 121, 6, 2012, p. 1-39.

KLAUS DITTRICH é doutor em História pela University of Portsmouth, no Reino Unido. Atualmente é professor assistente na Korea University em Seul, Coréia do Sul e interessa-se pela circulação de saberes entre Europa e Ásia.

Endereço: Korea University, Department of Korean History, Anam-dong 5-ga, Seongdong-gu, Seoul - South Korea - 136-701

E-mail: dittrich@korea.ac.kr.

Recebido em 29 de novembro de 2012.

Aceito em 13 de março de 2013. 